Review

\title{
Advances in Metabolic Engineering of Cyanobacteria for Photosynthetic Biochemical Production
}

\author{
Martin C. Lai ${ }^{1}$ and Ethan I. Lan ${ }^{2, *}$
}

1 Undergraduate Honors Program of Nano Science and Engineering, National Chiao Tung University, Hsinchu 300, Taiwan; E-Mail: martinnctu@hotmail.com

2 Department of Biological Science and Technology, National Chiao Tung University, Hsinchu 300, Taiwan

* Author to whom correspondence should be addressed; E-Mail: ethanilan@nctu.edu.tw; Tel.: +886-3-571-2121 (ext. 59719); Fax: +886-3-575-1898.

Academic Editor: Peter Meikle

Received: 2 July 2015 / Accepted: 22 October 2015 / Published: 27 October 2015

\begin{abstract}
Engineering cyanobacteria into photosynthetic microbial cell factories for the production of biochemicals and biofuels is a promising approach toward sustainability. Cyanobacteria naturally grow on light and carbon dioxide, bypassing the need of fermentable plant biomass and arable land. By tapping into the central metabolism and rerouting carbon flux towards desirable compound production, cyanobacteria are engineered to directly convert $\mathrm{CO}_{2}$ into various chemicals. This review discusses the diversity of bioproducts synthesized by engineered cyanobacteria, the metabolic pathways used, and the current engineering strategies used for increasing their titers.
\end{abstract}

Keywords: metabolic engineering; cyanobacteria

\section{Introduction}

Increasing concerns over energy and environmental problems prompted the need to develop renewable chemicals and fuels. Advances in genetic manipulation and genomics understanding enabled rapid advancement of microbial cell factory development. Once the enzymatic and genetic information for metabolic pathways producing important commodity biochemicals are solved, these genetic parts are then transferred to other organisms capable of utilizing diverse bioresources for growth. Among the 
various microbial systems, cyanobacteria have received an enormous amount of attention in recent years. Cyanobacteria are photosynthetic prokaryotes that grow through the direct utilization of sunlight and $\mathrm{CO}_{2}$. Cyanobacteria generate ATP and NADPH through oxygenic photosynthesis, and subsequently use them to fix $\mathrm{CO}_{2}$ into central metabolite through the Calvin-Benson-Bassham (CBB) cycle (Figure 1). By tapping into the metabolism of cyanobacteria, central metabolites may be directly transformed into desired biochemicals. This approach bypasses the need of repeated construction and deconstruction of plant biomass, which potentially increases the overall solar energy conversion efficiency.
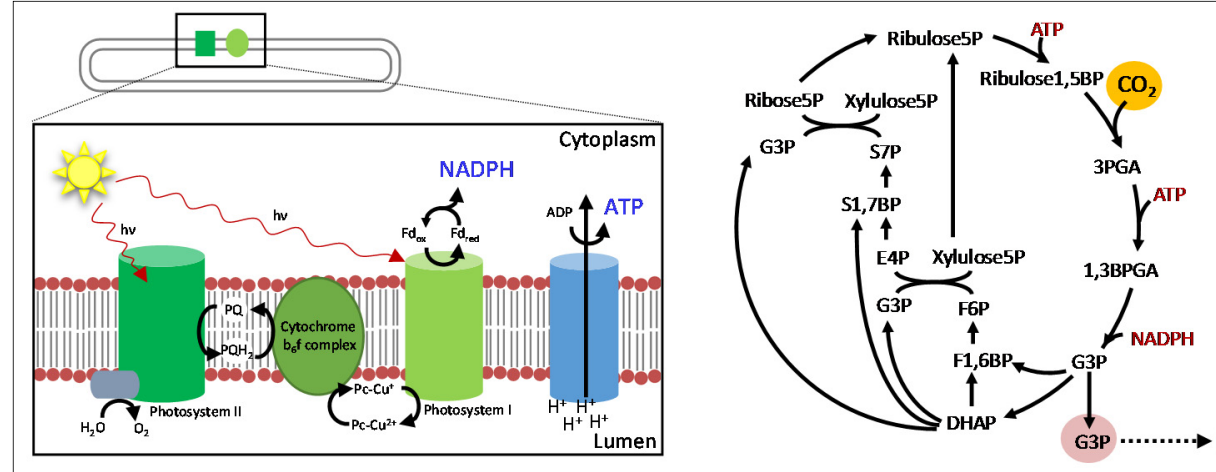

Figure 1. Schematics of cyanobacterial central metabolism. NADPH and ATP are generated through light reactions. Subsequently, they are used to convert $\mathrm{CO}_{2}$ into central metabolites, which can be used for biochemical synthesis.

Most commonly used cyanobacterial models (Table 1) are Synechococcus elongatus PCC 7942, Synechocystis PCC 6803, Synechococcus sp. PCC 7002, and Anabaena sp. PCC 7120 (hereafter referred to as PCC 7942, PCC 6803, PCC 7002, and PCC 7120, respectively). The genomes of these model cyanobacteria have been sequenced. In addition, these sequences have been organized and compiled into databases, such as cyanobase [1], for rapid access. The construction of these genome databases enabled the interpretation of cyanobacterial metabolism and facilitated the development of recombinant engineering. In addition, metabolomics analyses on these cyanobacteria have been reported [2-4]. This information, together with the construction of metabolic models [5-7], is useful for both understanding the basic metabolism of cyanobacteria and achieving higher level of metabolic redirection and control. PCC 7942 and PCC 6803 are freshwater cyanobacteria, while PCC 7002 is a marine species with the additional advantage of having higher salt tolerance. PCC 7120 is diazotrophic, which means it can utilize $\mathrm{N}_{2}$ as nitrogen source. With the exception of PCC 7120, all other model strains are naturally competent [8,9]. PCC 7120 transformation have been carried out through conjugation [10].

Cyanobacterial carbon and energy metabolisms differ significantly from that of heterotrophs commonly used in fermentation. As a result, additional metabolic engineering strategies such as changing reducing cofactor preference from NADH to NADPH, expressing pathways with higher thermodynamic driving force, and expressing transporters for excretion of products are often needed. Here we summarize the advances made in the metabolic engineering of cyanobacteria for the production of biochemicals and discuss the strategies and pathways used to improve their productivities. Table 2 is a comprehensive list containing biochemical targets, genes and promoters used, and production titers. The relevant metabolites associated with each biochemical target are also included in Table 2 . 
Table 1. Model cyanobacteria strains.

\begin{tabular}{|c|c|c|c|c|}
\hline Strain & Synechocystis PCC 6803 & Synechococcus sp. PCC 7002 & Synechococcus elongatus PCC 7942 & Anabaena sp. 7120 \\
\hline Genome & $\begin{array}{c}\text { 3.6 Mb Chromosome }+7 \text { plasmids } \\
\text { size ranging from } 2.3 \text { to } 120 \mathrm{~kb}\end{array}$ & $\begin{array}{c}3.0 \mathrm{Mb} \text { chromosome }+6 \text { plasmids } \\
\text { size ranging from } 4.8 \text { to } 186 \mathrm{~kb}\end{array}$ & 2.7 Mb Chromosome $+46 \mathrm{~kb}$ plasmid & $\begin{array}{c}6.4 \mathrm{Mb} \text { chromosome }+6 \text { plasmids } \\
\text { size ranging from } 5.6 \text { to } 408 \mathrm{~kb}\end{array}$ \\
\hline Description & Freshwater & Salt tolerant & Freshwater & Diazotrophic \\
\hline Transformation & Naturally competent & Naturally competent & Naturally competent & Conjugation \\
\hline
\end{tabular}

Table 2. Chemical targets, promoters used, genes expressed, titer, and relevant central metabolites.

\begin{tabular}{|c|c|c|c|c|c|c|c|c|c|}
\hline Chemical Target & Strain & Promoter(s) Used & Gene(s) Expressed & $\begin{array}{c}\text { Gene } \\
\text { Knockout(s) }\end{array}$ & $\begin{array}{c}\text { Titer } \\
(\mathrm{mg} / \mathrm{L})\end{array}$ & $\begin{array}{c}\text { Days of } \\
\text { Cultivation }\end{array}$ & $\begin{array}{c}\text { Relevant Central } \\
\text { Metabolite } \\
\end{array}$ & Comments & Ref. \\
\hline Ethanol & PCC 6803 & Prbc & $p d c, a d h 2$ & phb & 5500 & 26 & Pyruvate & Two copies of $p d c$, optimized cultivation & [11] \\
\hline Ethanol & PCC 6803 & PpsbA2 & $p d c, a d h$ & & 550 & 6 & Pyruvate & Decarboxylation of pyruvate serves as efficient driving force & [12] \\
\hline Ethanol & PCC 7942 & Ptrc & $p d u P, y q h D$ & & 182 & 10 & Acetyl-CoA & Oxygen tolerant aldehyde dehydrogenase & [13] \\
\hline Ethanol & PCC 7942 & PrbcLS & $p d c, a d h$ & & 0.02 & 7 & pyruvate & expression of $p d c$ and $a d h$ on plasmid & [14] \\
\hline Isopropanol & PCC 7942 & Ptrc & thl-atoAD-adc-adh & & 146 & 15 & Acetyl-CoA & Medium optimization, 2 phase cultivation & [15] \\
\hline Isopropanol & PCC 7942 & Ptrc & thl-atoAD-adc-adh & & 26.5 & 9 & Acetyl-CoA & decarboxylation of acetoacetate traps carbon to acetone & [16] \\
\hline 1-Butanol & PCC 7942 & Ptrc/PLlacO1 & $\begin{array}{c}\text { ter/nphT7, pduP } \\
y q h D, c r t, h b d\end{array}$ & & 317 & 12 & Acetyl-CoA & Oxygen tolerant aldehyde dehydrogenase & [13] \\
\hline 1-Butanol & PCC 7942 & Ptrc/PLlacO1 & $\begin{array}{l}\text { ter/nphT7, bldh, } \\
y q h D, c r t, h b d\end{array}$ & & 30 & 17 & Acetyl-CoA & ATP driving force through acetoacetyl-CoA synthase & [17] \\
\hline 1-Butanol & PCC 7942 & Ptrc/PLlacO1 & $\begin{array}{l}\text { ter/atoB, adhE2, } \\
\qquad r r t, h b d\end{array}$ & & 14.5 & 7 & Acetyl-CoA & Dark anaerobic incubation & [18] \\
\hline Isobutyraldehyde & PCC 7942 & Ptrc/PlacO1 & kivd/alsS-ilvC-ilvD & & 1100 & 8 & Pyruvate & $\begin{array}{l}\text { Decarboxylation of KIV serves as effective driving force. } \\
\text { In situ product removal }\end{array}$ & [19] \\
\hline Isobutanol & PCC 6803 & Ptac & kivD, adhA & & 240 & 21 & Pyruvate & Oleyol alcohol trap & [20] \\
\hline Isobutanol & PCC 7942 & Ptrc & $k v i d, Y q h D$ & & 450 & 6 & Pyruvate & $\begin{array}{l}\text { Decarboxylation of KIV serves as effective driving force. } \\
\text { In situ product removal }\end{array}$ & [19] \\
\hline 2-Methylbutanol & PCC 7942 & Ptrc & $\begin{array}{c}k i v D, y q h D, \operatorname{cim} A \\
\text { leuBCD }\end{array}$ & & 178 & 12 & $\begin{array}{c}\text { Pyruvate/ } \\
\text { acetyl-CoA }\end{array}$ & decarboxylation, native highly active AHAS & {$[21]$} \\
\hline
\end{tabular}


Table 2. Cont.

\begin{tabular}{|c|c|c|c|c|c|c|c|c|c|}
\hline Chemical Target & Strain & Promoter(s) Used & Gene(s) Expressed & $\begin{array}{c}\text { Gene } \\
\text { Knockout(s) }\end{array}$ & $\begin{array}{c}\text { Titer } \\
(\mathrm{mg} / \mathrm{L})\end{array}$ & $\begin{array}{c}\text { Days of } \\
\text { Cultivation } \\
\end{array}$ & $\begin{array}{c}\text { Relevant Central } \\
\text { Metabolite } \\
\end{array}$ & Comments & Ref. \\
\hline Fatty alcohol & PCC 6803 & Prbc & jojoba $F A R$ & & 0.2 & 18 & Acetyl-CoA & $\begin{array}{l}\text { using native fatty-acyl-ACP synthesis \& expression of } \\
\text { jojoba FAR }\end{array}$ & {$[22]$} \\
\hline Fatty alcohol & PCC 6803 & Prbc/PpsbA2 & jojoba FAR/aas & & 0.17 & 10 & Acetyl-CoA & $\begin{array}{l}\text { expression of jojoba FAR \& overexpression of } \\
\text { acyl-ACP synthetase }\end{array}$ & [23] \\
\hline 1,2-Propanediol & PCC 7942 & Ptrc & $\begin{array}{c}s A D H \\
\text { (C.beijerinkii), } \\
y q h D, m g s A\end{array}$ & & 150 & 10 & Pyruvate & NADPH utilization & [24] \\
\hline 2,3-Butanediol & PCC 6803 & Ptrc & als, aldc, ar & & 585 & 29 & Pyruvate & Codon optimization & [25] \\
\hline 2,3-Butanediol & PCC 7942 & PLlacO1 & als $S, a l s D, a d h$ & & 2380 & 20 & Pyruvate & $\begin{array}{l}\text { pyruvate pool coupled to decarboxylation and product } \\
\text { low toxicity }\end{array}$ & [26] \\
\hline Glycerol & PCC 6803 & Ptrc & gpp2 & & 1068 & 17 & DHAP & $\begin{array}{l}\text { Salt stress can stimulate glycerol production even in wildtype } \\
\text { for about } 0.7 \mathrm{mM}\end{array}$ & [27] \\
\hline Glycerol & PCC 7942 & Ptrc & gppl & & 1170 & 20 & DHAP & aeration, thermodynamically favorable glycerol phosphatase & [28] \\
\hline D-Lactate & PCC 6803 & Ptrc & gldA101, sth & & 1140 & 24 & Pyruvate & $\begin{array}{l}\text { expression of transhydrogenase, codon optmized mutated } \\
\text { glycerol dehydrogenase, addition of acetate helped production }\end{array}$ & [29] \\
\hline D-Lactate & PCC 6803 & Pcpc560 & Dldh & pta,phaCE & 1060 & 4 & Pyruvate & $\begin{array}{l}\text { knockout of PHB synthesis \& acetate formation, expression } \\
\text { codon optimized } l d h \text { from Lactobacillus delbrueckii }\end{array}$ & {$[30]$} \\
\hline D-Lactate & PCC 7942 & Ptrc & $l d h D, l l d P$ & & 829 & 10 & Pyruvate & expression of lactate transporter, engineered Ldh to use NADPH & [31] \\
\hline D-Lactate & PCC 7942 & Plac & $l d h A, l l d P, u d h A$ & & 55 & 4 & Pyruvate & Expression of LldP protein from E. coli (transporter) & [32] \\
\hline L-Lactate & PCC 6803 & Ptrc & $l d h$ & & 1800 & 40 & Pyruvate & Long term production & [33] \\
\hline L-Lactate & PCC 6803 & Ptrc2/Ptrc2 & $p k / l d h$ & $\begin{array}{c}\text { knockdown } \\
P P C\end{array}$ & 837 & 14 & Pyruvate & codon optimization \& natural copy & [34] \\
\hline L-Lactate & PCC 6803 & Ptrc/Ptrc & $l d h / s t h$ & & 288 & 14 & Pyruvate & expression of transhydrogenase, Bacillus subtilis Ldh & [35] \\
\hline L-Lactate & PCC 6803 & PpsbA2 & $l d h, l d h P$ & & 15.3 & 18 & Pyruvate & Tested various $l d h$ genes. & [36] \\
\hline 3-Hydroxypropionate & PCC 7942 & Ptrc & $m c r, m s r$ & & 659 & 16 & Acetyl-CoA & $\begin{array}{l}\text { selection of best performing malonate semialdehyde reductase } \\
\text { (Msr), two NADPH utilizing steps }\end{array}$ & [37] \\
\hline 3-Hydroxypropionate & PCC 7942 & Ptrc & gppl, dhaB, рииC & & 31.7 & 10 & DHAP & oxygen sensitive, Dark anaerobic with nutrient limitation & [28] \\
\hline
\end{tabular}


Table 2. Cont.

\begin{tabular}{|c|c|c|c|c|c|c|c|c|c|}
\hline Chemical Target & Strain & Promoter(s) Used & Gene(s) Expressed & $\begin{array}{c}\text { Gene } \\
\text { Knockout(s) }\end{array}$ & $\begin{array}{c}\text { Titer } \\
(\mathrm{mg} / \mathrm{L})\end{array}$ & $\begin{array}{c}\text { Days of } \\
\text { Cultivation }\end{array}$ & $\begin{array}{c}\text { Relevant Central } \\
\text { Metabolite } \\
\end{array}$ & Comments & Ref. \\
\hline 3-Hydroxybutyrate & PCC 6803 & Ptca/Ptac & tesB/phaA-phaB & & 533 & 21 & Acetyl-CoA & Nutrient limitation, NADPH & [38] \\
\hline Itaconic acid & PCC 6803 & Ptac & cad & & 14.5 & 16 & Isocitrate & Expression of $\mathrm{cad}$ & [39] \\
\hline $\mathrm{p}$-Coumaric acid & PCC 6803 & PpsbA2 & sam8 & $\begin{array}{l}\text { slr1573 } \\
\text { (laccase) }\end{array}$ & 82.6 & 4 & Tyrosine & $\begin{array}{l}\text { knockout of competing pathway for phenolic } \\
\text { compound degradation }\end{array}$ & [40] \\
\hline Fatty acids & PCC 6803 & Ptrc/Pcpc/Prbc & $\begin{array}{l}\text { tes } A, \text { fatB1, fatB2/ } \\
\text { accBC/accDA, } \\
\quad \text { fat } B 2\end{array}$ & $\begin{array}{l}\text { aas, pta, phb } \\
\text { genes, (see } \\
\text { comments) }\end{array}$ & 197 & 2 & Acetyl-CoA & $\begin{array}{l}\text { construct six generation strain: extensive knock outs of PHB } \\
\text { synthesis, peptidoglycan layer protein, hemolysin-like surface } \\
\text { layer protein, cyanophycin synthesis }\end{array}$ & [41] \\
\hline Fatty acids & PCC 7002 & Ptrc/PpsbA1 & tesA/rbcLS & $f a d D$ & 131 & 20 & Acetyl-CoA & Overexpression of rubisco & [42] \\
\hline Fatty acids & PCC 7942 & Ptrc & $\operatorname{tes} A$ & aas & 45 & 20 & Acetyl-CoA & knockout of acylACP synthetase blocks utilization of fatty acids & [43] \\
\hline Fatty acids & PCC 7942 & Ptrc/PpsbA1 & fat1/rbcLS & aas & 35 & 20 & Acetyl-CoA & overexpression of ACCase hurts production & [44] \\
\hline D-Mannitol & PCC 7002 & PpsbA & $m t l D, m l p$ & $\operatorname{glg} A 1, \operatorname{glg} A 2$ & 1100 & 12 & F6P & codon optimization, artificial carbon sink & [45] \\
\hline Hexose & PCC 7942 & Ptrc & glf, invA, galU & & 45 & 5 & Glc6P & expression of sugar transporter & [32] \\
\hline Sucrose & PCC 7942 & Ptrc & $\csc B$ & inv $A, g \lg C$ & 2700 & 7 & Glc6P & Salt stress, knockout of natural carbon/electron sink & [46] \\
\hline Sucrose & PCC 6803 & PpetE & $c s c B, s p s, s p p, u g p$ & $\operatorname{ggp} S, \operatorname{ggt} C D$ & 140 & 10 & Glc6P & $\begin{array}{l}\text { Salt stress, knockout of competing pathways, expression of } \\
\text { sucrose synthesis genes }\end{array}$ & [47] \\
\hline Glucosylglycerol & PCC 6803 & -- & -- & $\operatorname{ggt} C D, \operatorname{ggp} R$ & 981 & 24 & G3P/Glc6P & salt shock, hypoosmotic shock & [48] \\
\hline Ethylene & PCC 6803 & Ptrc & efe & & \multicolumn{2}{|c|}{$240 \mathrm{~nL} / \mathrm{mL} / \mathrm{d}$} & $\alpha$-Ketoglutarate & compared various promoters, used plasmid based expression & [49] \\
\hline Ethylene & PCC 6803 & PpsbA & efe & & \multicolumn{2}{|c|}{$171 \mathrm{mg} / \mathrm{L} / \mathrm{d}$} & $\alpha$-Ketoglutarate & Multiple copies of EFE & [50] \\
\hline Ethylene & PCC 7942 & Ptrc & $\begin{array}{l}\text { ACS-Ctdoc-ACO- } \\
\quad \text { Acdoc-Cip } 2 \\
\end{array}$ & & \multicolumn{2}{|c|}{$81.6 \mathrm{~nL} / \mathrm{mL} / \mathrm{d} / \mathrm{OD}$} & SAM & Chimeric protein fusion & [51] \\
\hline Ethylene & PCC 7942 & PpsbA1 & efe & & \multicolumn{2}{|c|}{$10.82 \mu \mathrm{L} / \mathrm{mL} / \mathrm{D} / \mathrm{OD}$} & $\alpha$-Ketoglutarate & $\begin{array}{l}\text { choose a strong promoter site in } 7942 \text { and rps12-mediated } \\
\text { gene replacement }\end{array}$ & [52] \\
\hline Isoprene & PCC 6803 & PpsbA2 & $\begin{array}{c}\text { IspS (Pueraria } \\
\text { montana })\end{array}$ & & 0.35 & 8 & G3P/Pyruvate & Gaseous/aqueous two-phase photobioreactor & [53] \\
\hline Isoprene & PCC 6803 & PpsbA2 & $\begin{array}{l}\text { IspS, hmgS, hmgR, } \\
\text { fni, } m k, p m d, p m k\end{array}$ & & 0.3 & 8 & Acetyl-CoA & expression of both pathways to IPP increases isoprene production & [54] \\
\hline
\end{tabular}


Table 2. Cont.

\begin{tabular}{|c|c|c|c|c|c|c|c|c|c|}
\hline Chemical Target & Strain & Promoter(s) Used & Gene(s) Expressed & $\begin{array}{c}\text { Gene } \\
\text { Knockout(s) } \\
\end{array}$ & $\begin{array}{c}\text { Titer } \\
(\mathrm{mg} / \mathrm{L})\end{array}$ & $\begin{array}{c}\text { Days of } \\
\text { Cultivation } \\
\end{array}$ & $\begin{array}{c}\text { Relevant Central } \\
\text { Metabolite } \\
\end{array}$ & Comments & Ref. \\
\hline Isoprene & PCC 6803 & PpsbA2 & $\begin{array}{c}\text { IspS (Pueraria } \\
\text { montana) }\end{array}$ & & \multicolumn{2}{|c|}{$50 \mu \mathrm{g} / \mathrm{gDCW} / \mathrm{d}$} & G3P/Pyruvate & Expression of isoprene synthase & {$[55]$} \\
\hline Limonene & PCC 6803 & Ptrc & $\begin{array}{c}\operatorname{limS} \text { (Schizonepeta } \\
\text { tenuifolia), dxs, } \\
\text { crtE, ipi } \\
\end{array}$ & & 1 & 30 & G3P/Pyruvate & codon optimization, enhancing flux through MEP pathway & {$[56]$} \\
\hline Limonene & PCC 7002 & PcpcBA & $\begin{array}{l}\text { limS (Mentha } \\
\text { spicata) }\end{array}$ & & 4 & 4 & G3P/Pyruvate & product trap by dodecane overlayLan & {$[57]$} \\
\hline Limonene & PCC 7120 & Pnir::PpsbA1 & $\begin{array}{c}\text { limS (Picea } \\
\text { sitchensis), dxs, } \\
\text { ipphp, gpps }\end{array}$ & & 0.52 & 12 & G3P/Pyruvate & $\begin{array}{l}\text { enhancing flux through MEP pathway by gene } \\
\text { overexpression, high light density }\end{array}$ & [58] \\
\hline Farnesene & PCC 7120 & Pnir, PpsbA1 & faS (Picea abies) & & 0.31 & 15 & G3P/Pyruvate & codon optimization & [59] \\
\hline Bisabolene & PCC 7002 & PcpcBA & bis (Abies grandis) & & 0.6 & 4 & G3P/Pyruvate & product trap by dodecane overlay & [57] \\
\hline Tocopherols & PCC 6803 & PnirA & $\begin{array}{l}\text { hpd (Arabidopsis } \\
\text { thaliana) }\end{array}$ & & $0.250 \mathrm{mg} / \mathrm{gDCW}$ & 12 & G3P/Pyruvate & Nitrate inducible promoter & {$[60]$} \\
\hline$\beta$-Caryophyllene & PCC 6803 & PpsbA2 & QHSI & & 0.046 & 7 & G3P/Pyruvate & $\begin{array}{l}\text { use similar pathway in } 6803 \text { to produce plant's second } \\
\text { metabolite, only need few key enzyme }\end{array}$ & [61] \\
\hline$\beta$-Phellandrene & PCC 6803 & PpsbA2-trc-T7 & $\begin{array}{c}\text { PLHS (Lavandula } \\
\text { angustifolia) }\end{array}$ & & 0.9 & 2 & G3P/Pyruvate & codon optimization, High light with psba2-trc-T7 fused promoter & [62] \\
\hline$\beta$-Phellandrene & PCC 6803 & PpsbA2 & $\begin{array}{l}\text { PHLS (Lavandula } \\
\text { angustifolia) }\end{array}$ & & 0.2 & 8 & G3P/Pyruvate & codon optimization & [63] \\
\hline Dihydroxyacetone & PCC 7942 & Ptrc & gppl, dhaD & & 78.6 & 16 & DHAP & NAD-dependent DhaD could not efficiently reduce glycerol & [28] \\
\hline Acetone & PCC 6803 & Prbc/Pcpc & cftAB/adc & phaCE,pta & 36 & 4 & Acetyl-CoA & Increasing acetyl-CoA pool & [64] \\
\hline Alkanes & PCC 7120 & Pado & $\begin{array}{c}\text { aar, ado } \\
\text { (A. halophytica) } \\
\end{array}$ & & $1.25 \mathrm{mg} / \mathrm{gDCW}$ & 5 & Acetyl-CoA & Salt stress & [65] \\
\hline
\end{tabular}




\section{Short Chain Alcohols}

\subsection{Ethanol}

Some cyanobacteria naturally produce small amounts of ethanol under fermentative conditions [66]. However, genetic engineering was necessary to increase the productivity and enable production under photosynthetic conditions. Ethanol production from PCC 7942 [14] has been demonstrated as early as the late 20th century. While the productivity $\left(54 \mathrm{nmol} / \mathrm{L} / \mathrm{d} / \mathrm{OD}_{730}\right)$ is relatively low, it is the first alcohol produced from genetically modified cyanobacteria. Ten years later, an ethanol production titer of $550 \mathrm{mg} / \mathrm{L}$ with a productivity of $5.2 \mathrm{mmol} / \mathrm{L} / \mathrm{d} / \mathrm{OD}_{730}$ from PCC 6803 [12] was achieved using photobioreactor. In both PCC 7942 and PCC 6803, ethanol was produced using the pyruvate decarboxylation pathway from Zymomonas mobilis (Figure 2), employing pyruvate decarboxylase (Pdc) and alcohol dehydrogenase (Adh). Pyruvate decarboxylation is an irreversible reaction and therefore provides a strong driving force for acetaldehyde formation. Decarboxylation is a good example of a powerful driving force for product formation because the gaseous $\mathrm{CO}_{2}$ leaves the system, pulling the carbon flux towards the product. It is uncertain why the first ethanol report using PCC 7942 was significantly less successful than using PCC 6803. However, it is possible that the gene expression was more stable in the PCC 6803 study as the two genes were introduced into the genome rather than using a plasmid based system.

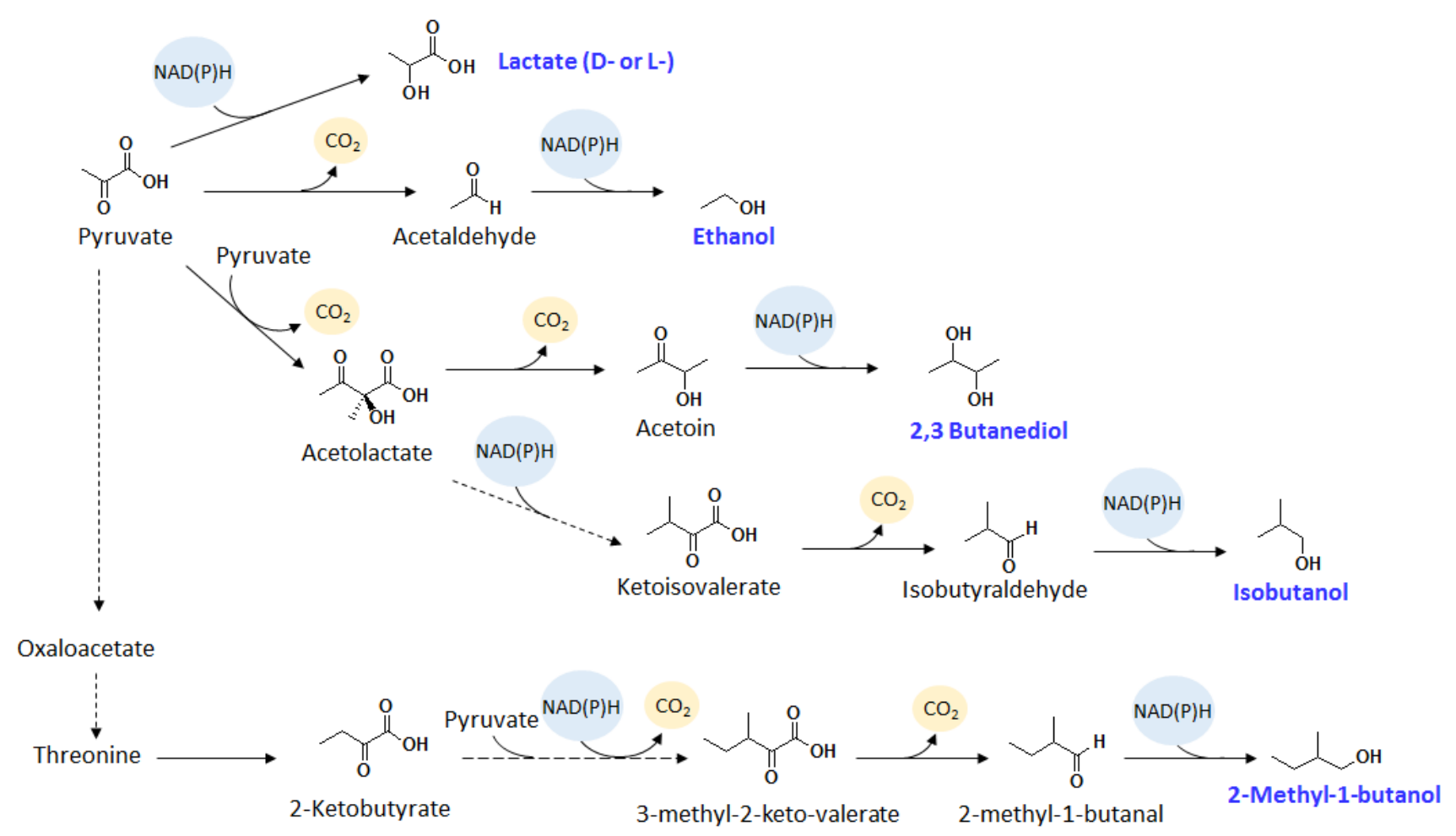

Figure 2. Schematics of pyruvate derived bioproducts. Dashed lines represent multiple enzymatic steps. Evolution of $\mathrm{CO}_{2}$ serves as effective driving force for product formation.

To further increase the titer of ethanol production, additional optimization was carried out [11]. In this study, PCC 6803 endogenous alcohol dehydrogenase was expressed instead of that from Z. mobilis. In addition, the expression of multiple copies of the $p d c$ and $a d h$ increased the gene dosage. 
In situ ethanol removal using gas stripping further improved ethanol productivity. As ethanol is continuously removed from the culture, equilibrium further favors to push carbon flux towards ethanol. Through both genetic and cultivation optimizations, ethanol production reached a titer of $5.5 \mathrm{~g} / \mathrm{L}$ in 26 days, representing the highest biochemical production titer demonstrated in the cyanobacterial engineering literature.

Alternatively, ethanol can also be produced from acetyl-CoA (Figure 3). Ethanol production from acetyl-CoA is mediated by a bifunctional aldehyde/alcohol dehydrogenase AdhE in a reversible reaction. AdhE is known to be oxygen sensitive, and therefore its functional expression in cyanobacteria would be difficult. To bypass AdhE, the expression of separate oxygen tolerant CoA-acylating aldehyde dehydrogenase and alcohol dehydrogenase effectively converts acetyl-CoA to ethanol via acetaldehyde under aerobic conditions [13]. By expressing PduP, an oxygen tolerant CoA-acylating aldehyde dehydrogenase from the 1,2-propanediol degradation pathway from Salmonella enterica, and YqhD, a NADPH dependent alcohol dehydrogenase, PCC 7942 was engineered to produce ethanol from acetyl-CoA. The resulting strain produced $182 \mathrm{mg} / \mathrm{L}$ of ethanol in 10 days. It is worth noting that this pathway requires two reducing cofactors. While the consumption of two reducing cofactors drives the synthesis of ethanol, these results potentially indicate that decarboxylation serves as a stronger driving force for ethanol production.

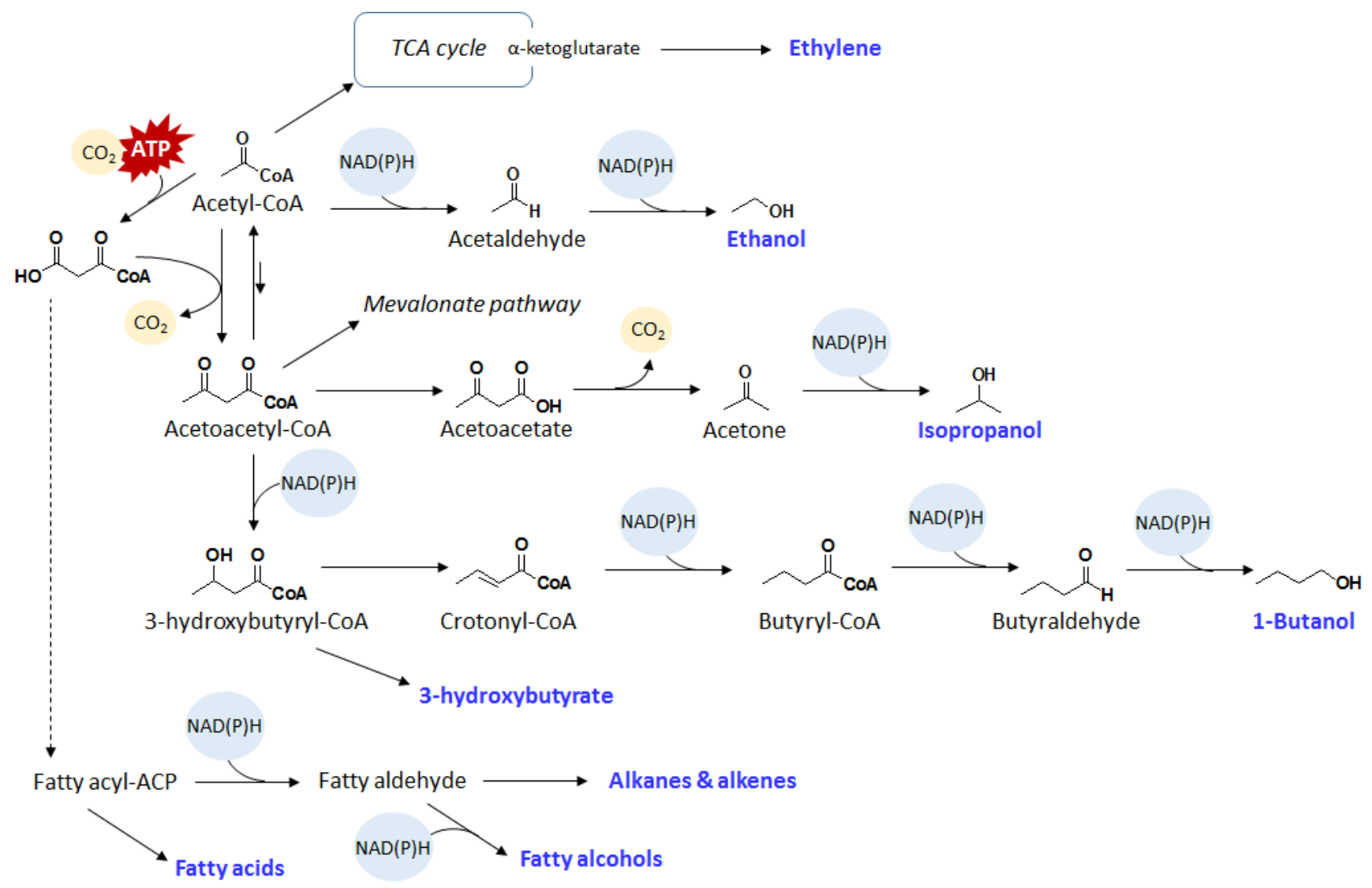

Figure 3. Schematics of acetyl-CoA derived bioproducts. Dashed lines represent multiple enzymatic steps. 


\subsection{Isopropanol}

Isopropanol is a natural fermentation product from certain microbes. Industrially, isopropanol is widely used as a solvent and can be dehydrated into propylene, a petroleum-derived monomer for the production of the widely used plastic, polypropylene. The production pathway for isopropanol begins with acetyl-CoA condensation to acetoacetyl-CoA, which is followed by the removal of the CoA moiety to form acetoacetate. Acetoacetate is then decarboxylated into acetone, which is subsequently reduced to isopropanol (Figure 3). Isopropanol production pathway and genes were introduced into PCC 7942 [16]. Despite the expectation that the isopropanol pathway has a decarboxylation as driving force, the resulting strain was not able to produce isopropanol under photosynthetic conditions. Further analysis through acetate feeding showed that the acetyl-CoA level in PCC 7942 is insufficient to support isopropanol production. As an alternative approach, cyanobacteria expressing isopropanol production genes were incubated in the dark without nitrogen and phosphorus. Under nutrient limiting conditions, the acetyl-CoA flux was hypothesized to increase. As a result, $26.5 \mathrm{mg} / \mathrm{L}$ of isopropanol was observed [16]. With further optimization of cultivation conditions, isopropanol production has been increased to $146 \mathrm{mg} / \mathrm{L}$ [15].

In another study aimed at producing acetone, the precursor to isopropanol, using engineered PCC 6803, acetate forming genes were disrupted to increase the pool of intracellular acetyl-CoA [64]. This approach increased the acetone production six-fold reaching a titer of $36 \mathrm{mg} / \mathrm{L}$ in four days. Together, these results indicated that in addition to decarboxylation, increasing the substrate pool is also an important design principle.

\subsection{Isobutanol}

The isobutanol production pathway utilizes valine biosynthesis. The valine precursor, ketoisovalerate, is decarboxylated to isobutyraldehyde, which can be directly reduced into isobutanol via alcohol dehydrogenase (Figure 2). An isobutanol pathway without alcohol dehydrogenase was first expressed in PCC 7942 [19]. The resulting strain produced isobutyraldehyde with a titer of $1.1 \mathrm{~g} / \mathrm{L}$ using in situ product removal through gas stripping. Aldehydes are generally toxic to life. Therefore, in situ product removal lowers the toxic effect of isobutyraldehyde production to cyanobacteria. Isobutyraldehyde was further converted to isobutanol in PCC 7942 with additional expression of alcohol dehydrogenase YqhD. The resulting strain produced $450 \mathrm{mg} / \mathrm{L}$ of isobutanol in six days.

In another study, the isobutanol pathway was expressed in PCC 6803 [20]. In shake flask experiment, $90 \mathrm{mg} / \mathrm{L}$ of isobutanol was observed in six days. Further improvement using oleyl alcohol as a product trap to remove butanol from the culture increased the production titer up to $240 \mathrm{mg} / \mathrm{L}$. This result also demonstrated the usefulness of product removal.

\subsection{1-Butanol}

1-Butanol is a natural fermentation product from certain Clostridium species. 1-Butanol production in non-native organisms has been difficult due the enzyme oxygen sensitivity and less well-defined redox reactions. One of the key enzymes of the Clostridium butanol pathway is the butyryl-CoA dehydrogenase electron transferring protein complex. This enzyme was difficult to express in heterologous organisms because it requires association with ferredoxin and is oxygen sensitive. This difficulty was overcome by 
replacing this enzyme complex with a trans-enoyl-CoA reductase (Ter) [67,68]. Ter directly utilizes NADH as the reducing cofactor for the reduction of crotonyl-CoA to butyryl-CoA (Figure 3) with a large negative change in free energy, making it irreversible and thus serving as an effective driving force for this pathway.

This modified 1-butanol pathway was subsequently transferred to PCC 7942 [18]. However, the resulting strain did not produce 1-butanol under photosynthetic conditions. 1-Butanol was produced only under dark anaerobic conditions [18]. One difficulty was that that the first reaction of the pathway catalyzed by thiolase is thermodynamically unfavorable with $\mathrm{K}_{\mathrm{eq}}$ of $10^{-5}$. To circumvent this difficult step, an alternative route using malonyl-CoA was constructed [17]. Malonyl-CoA reacts with acetyl-CoA to form acetoacetyl-CoA in an irreversible reaction catalyzed by acetoacetyl-CoA synthase. Naturally, malonyl-CoA is the ATP activated product of acetyl-CoA through the acetyl-CoA carboxylase. Combining the reactions catalyzed by acetyl-CoA carboxylase and acetoacetyl-CoA synthase, the net reaction is two acetyl-CoA condensation to acetoacetyl-CoA at the expense of one ATP. This ATP hydrolysis serves as an energy input to convert the thermodynamically unfavorable acetyl-CoA condensation into a favorable reaction. The expression of acetoacetyl-CoA synthase with the butanol production pathway enabled the direct photosynthetic production of 1-butanol with a titer of $30 \mathrm{mg} / \mathrm{L}$.

1-Butanol production was further improved by the expression of an oxygen tolerant CoA-acylating aldehyde dehydrogenase [13]. The Clostridium aldehyde dehydrogenase is oxygen sensitive, which prohibits its functional expression in cyanobacteria under photosynthetic conditions. To solve this difficulty, the oxygen tolerant CoA-acylating aldehyde dehydrogenase of the 1,2-propanediol degradation pathway from $S$. enterica was used to replace the Clostridium aldehyde dehydrogenase. The resulting strain was able to produce about $300 \mathrm{mg} / \mathrm{L}$ of 1-butanol in 12 days, representing a 10-fold increase compared to the 1-butanol produced using the Clostridium aldehyde dehydrogenase. This result shows that the oxygen tolerance of enzymes is also very important for biochemical production using cyanobacteria.

\subsection{2-Methyl-1-Butanol}

In addition to isobutanol, other branched short chain alcohols are also biofuel candidates, which have superior properties over ethanol. 2-Methyl-1-butanol (2MB) is derived from 2-keto-3-methylvalerate (KMV), the precursor to isoleucine, through the same keto acid type pathway as the isobutanol production (Figure 2). KMV is derived from 2-ketobutyrate through the isoleucine biosynthesis. 2-Ketobutyrate is derived from either the cyanobacterial native threonine pathway or heterologous citramalate pathway. In a study where the citramalate pathway was expressed in PCC 7942 together with a ketoacid decarboxylase and an alcohol dehydrogenase, $2 \mathrm{MB}$ was produced with a titer of $178 \mathrm{mg} / \mathrm{L}$ in 12 days [21]. Interestingly, the isoleucine biosynthesis was not overexpressed, and yet $2 \mathrm{MB}$ was produced instead of 1-propanol. This result was surprising as the expression of the same set of genes in E. coli resulted in mostly 1-propanol production [69]. This study indicated that the native isoleucine genes were highly expressed and active in PCC 7942. The 2MB production pathway is analogous to the isobutanol pathway, therefore exhibiting similar characteristics and driving force properties. However, the production titer was lower than that of isobutanol. This is potentially due to lower substrate (2-ketobutyrate) pool and higher product toxicity. 


\section{Fatty Acids and Hydrocarbons}

\subsection{Fatty Acids}

Biodiesel is typically derived from chemically reacting lipids with short chain alcohols such as methanol, ethanol or propanol, into corresponding fatty esters. Instead of producing triacylglycerides, microbial systems can be engineered to directly produce fatty acids, which can also be esterified. Fatty acid production from PCC 6803 has been demonstrated with a titer of $197 \mathrm{mg} / \mathrm{L}$ in two days [41]. The expression of TesA, E. coli thioesterase with N-terminus periplasmic directing sequence deleted, and codon optimized plant thioesterases releases fatty acids from their fatty acyl-(acyl-carrier-protein) (ACP) precursors. Together with the deletion of genes encoding for fatty acid activation, polyhydroxybutyrate (PHB), S-layer, cyanophycin, and acetate biosynthesis, the final titer of fatty acid produced was increased from $1.8 \mathrm{mg} / \mathrm{L}$ to $197 \mathrm{mg} / \mathrm{L}$. Liu et al. [70] further demonstrated a strategy which enables cyanobacteria to degrade cellular membranes and release free fatty acids upon $\mathrm{CO}_{2}$ limitation. This fatty acid releasing strategy was accomplished by the expression of lipases under the promoter control of native inorganic carbon uptake system.

In another study, PCC 7002 was engineered to produce fatty acids with a titer of $131 \mathrm{mg} / \mathrm{L}$ in 20 days [42]. In particular, it was noted that PCC 7002 has a higher tolerance to fatty acids. In this study, it was found that the expression of heterologous RuBisCo, the primary enzyme responsible for $\mathrm{CO}_{2}$ fixation in $\mathrm{CBB}$ pathway, was able to increase the target productivity. Similar effect was also observed by Atsumi et al. [19] in the isobutanol production. While successful in increasing biochemical productivity, the effect of RuBisCo overexpression in carbon fixation rate has yet to be clarified.

\subsection{Fatty Alcohols and Hydrocarbons}

Many species of cyanobacteria naturally produce small quantities of hydrocarbons [71]. The hydrocarbon production pathway and its enzymes were identified [72,73]. Fatty acyl-ACP, the end product of fatty acid elongation, is reduced to fatty aldehyde by fatty acyl-ACP reductase. Fatty aldehyde decarbonylase then catalyzes the conversion of fatty aldehydes into alkanes or alkenes with formate as a byproduct.

Engineered PCC6803 has been demonstrated to produce fatty alcohols with a titer of around $0.2 \mathrm{mg} / \mathrm{L}$ through the expression of fatty acyl-CoA reductase from jojoba [22]. While hydrocarbon biosynthesis is natural to many cyanobacteria, overexpression of the genes involved in alkane biosynthesis in cyanobacteria has been used to increase alkane productivity [65,74,75]. However, compared to the higher productivity of fatty acids, both fatty alcohol and hydrocarbon productions are relatively low, indicating the presence of bottlenecks. It is likely that the key enzyme fatty acyl-ACP reductase is limiting, as the flux to fatty acyl-ACP is capable of supporting higher flux production of fatty acids. As an alternative to using acyl-ACP reductase, liberation of fatty acids followed by activation to acyl-CoAs allows the use of CoA-acylating aldehyde dehydrogenase, which has been shown to reduce to fatty aldehyde more efficiently in E. coli [76]. However, this pathway has yet to be tested in cyanobacteria. 


\section{Olefins}

\subsection{Ethylene}

Microbial ethylene production is catalyzed by the ethylene forming enzyme (Efe). Efe utilizes $\alpha$-ketoglutarate and produces succinate as a byproduct. Metabolic engineering of cyanobacteria for the production of ethylene has been reported as early as the 1990s [77,78]. However, the productivities reported were relatively low due to the instability of efe within the cyanobacteria as efe becomes truncated through successive subculturing [52]. This problem was addressed by eliminating the potential "hot spots" for mutation within efe through codon optimization [50]. In addition, efe was expressed in multiple copies, increasing gene dosage and therefore the overall enzymatic activity. The resulting engineered PCC 6803 strain was able to achieve significant improvement of ethylene production with a relatively high peak productivity of $171 \mathrm{mg} / \mathrm{L} / \mathrm{d}$. Ethylene production is the one of the few example which achieves higher productivity utilizing acetyl-CoA. PCC 6803 has also been engineered to co-utilize xylose, an abundant bioresource, for aiding ethylene production [79]. In addition, cyanobacterial ethylene production has also been achieved through the expression of plant ethylene formation pathway that utilizes S-adenyl-methionine (SAM) in two reaction steps [51]. SAM is first converted to methylthioadenosine and 1-aminocyclopropane-1-carboxylate. 1-aminocyclopropane-1-carboxylate is subsequently converted to ethylene, producing hydrogen cyanide and $\mathrm{CO}_{2}$ as byproducts. The resulting strain achieved $81.6 \mathrm{~nL} / \mathrm{mL} / \mathrm{d} / \mathrm{OD}$ [51].

\subsection{Isoprene}

Cyanobacteria and most other bacteria use the methyl-erythritol-4-phosphate (MEP) pathway (Figure 4) for the biosynthesis of isoprenoids. Isoprene, a five carbon diene, is the component of polyisoprene or latex, which is also an important target for renewable chemical production. Isoprene is synthesized from Dimethylallyl pyrophosphate (DMAPP) using isoprene synthase. Isoprene synthase is a natural enzyme found in plants, particularly in poplar and kudzu vine. Through heterologous expression of isoprene synthase in PCC 6803 [55], direct photosynthetic isoprene production was achieved. However, the productivity achieved $(50 \mu \mathrm{g} / \mathrm{gDCW} / \mathrm{d})$ was relatively low. To increase the productivity of isoprene production, the mevalonate pathway (Figure 4) was co-expressed with isoprene synthase in PCC 6803 [54]. With the additional knockout of glycogen synthesis, the resulting strain was able to produce up to 300 $\mu \mathrm{g} / \mathrm{L}$ of isoprene in eight days, representing several fold improvement over the strain expressing isoprene synthase only.

\subsection{Terpenoids}

Terpenoids represent a large class of bioactive molecules. In particular, some terpenoids are excellent targets for biofuel. Thus far, photosynthetic production of monoterpenes and sesquiterpenes has been demonstrated using engineered cyanobacteria. The chemical targets and their corresponding production titers are listed in Table 2. Monoterpene production follows the same MEP pathway as isoprenoids (Figure 4). DMAPP and its isomer isopentenyl diphosphate (IPP) react to form the ten carbon metabolite geranyl diphosphate (GPP). Both limonene and $\beta$-phellandrene are produced directly from GPP using 
limonene synthase and $\beta$-phellandrene synthase, respectively. Cyanobacterial engineering strategies for limonene and $\beta$-phellandrene production include the expression of MEP pathway genes for increasing pathway flux [58], dodecane overlay as product trap [57], and increased expression of limonene synthase through promoter engineering [62]. However, the resulting titers of monoterpene productions remain relatively low (around $1 \mathrm{mg} / \mathrm{L}$ ). Sesquiterpene biosynthesis elongates GPP into farnesyl diphosphate (FPP). Similar to the production of monoterpenes, biosynthesis of sesquiterpenes such as $\beta$-caryophyllene, farnesene, and bisabolene requires only the corresponding synthases. Recently, diterpene manoyl oxide, precursor to forskolin, production has been reported using engineered PCC 6803 [80]. Resulting titers (Table 2) of sesquiterpenes produced using engineered cyanobacteria were relatively low compared to other bioproducts. The bottleneck of terpenoids production using cyanobacteria has yet to be determined.

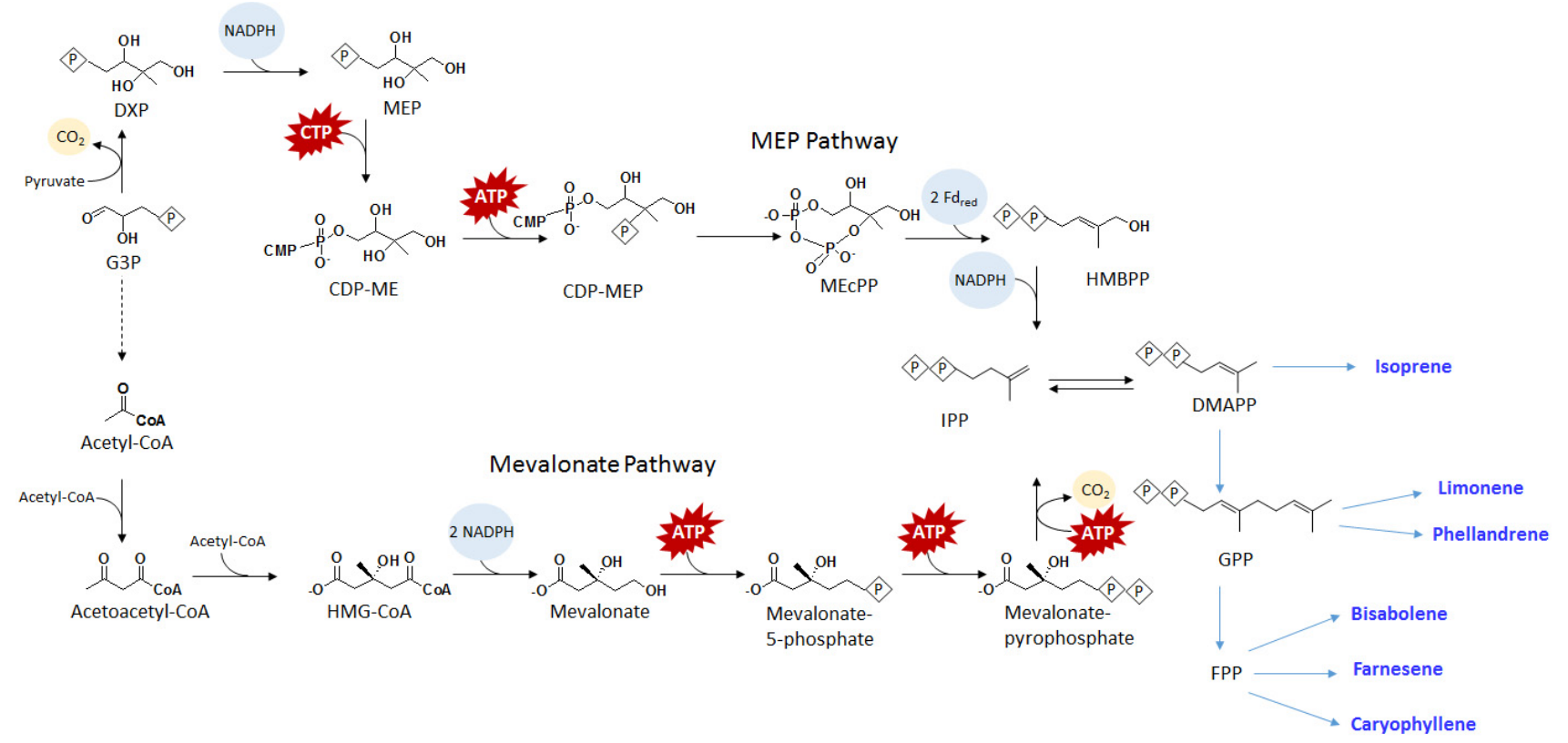

Figure 4. Schematics of mevalonate and MEP pathways for synthesizing isoprenoids and terpenoids. Symbol P inside a diamond represents phosphate. For abbreviations, see below in the abbreviations section.

\section{Organic Acids}

\subsection{Lactate}

Lactate fermentation is widely practiced both in food preparation and for renewable plastics. Among the current bioproducts produced by engineered cyanobacteria, lactate is one of the most extensively studied biochemical productions in cyanobacteria and produced with high productivity. Both isomers of lactate have been produced using cyanobacteria. Some engineering strategies involved in lactate production include the expressions of lactate transporters [32], transhydrogenase for converting NADPH produced by photosynthesis into $\mathrm{NADH}$ [35], and engineered lactate dehydrogenase (Ldh) for direct NADPH utilization [31], overexpression of pyruvate kinase to trap carbon flux into pyruvate from PEP [34], and knockouts of competing carbon sinks [30]. Currently, the highest lactate production demonstrated is $1.8 \mathrm{~g} / \mathrm{L}$ in 40 days. In addition, waste water from anaerobic digest rich in organics, nitrogen, and 
phosphorus, was used to aid photosynthetic lactate production [81] in PCC 6803, illustrating the beneficial application of mixotrophic cultivation.

\subsection{3-Hydroxybutyrate}

3-Hydroxyacids are the monomers of polyhydroxyalkanoates, which are biocompatiable and biodegradable thermoplastics or elastomeric materials. 3-Hydroxybutyrate $(3 \mathrm{HB}$ ) production pathway follows the butanol and isopropanol biosynthesis (Figure 3). Acetyl-CoA is used as the cellular metabolite to form acetoacetyl-CoA, which is followed by reduction to 3-hydroxybutyryl-CoA. Subsequently, 3-hydroxybutyryl-CoA undergoes a thioesterase catalyzed reaction to liberate $3 \mathrm{HB}$ and CoA. 3HB production pathway genes were introduced into PCC 6803 [38]. Similar to the isopropanol and butanol reports, production of $3 \mathrm{HB}$ is limited under photosynthetic conditions. Nevertheless, as nutrients become limited through consumption, the intracellular acetyl-CoA pool increases. The acetyl-CoA pool naturally increases in PCC 6803 upon nutrient depravation in order to synthesize PHB, a natural carbon storage. As increasing acetyl-CoA pool drives $3 \mathrm{HB}$ production, the resulting strain produced up to $533 \mathrm{mg} / \mathrm{L}$ of $3 \mathrm{HB}$ in 21 days.

\subsection{3-Hydroxpropionate}

One of the most well characterized 3-hydroxypropionate (3HP) production pathway utilizes glycerol as its precursor (Figure 5). Glycerol dehydrates to 3-hydroxypropionylaldehyde, which is subsequently oxidized to 3HP. PCC 7942 was engineered to produce $3 \mathrm{HP}$ with a titer of $31.7 \mathrm{mg} / \mathrm{L}$ in 10 days [28]. In this work, the glycerol dehydratase used was oxygen sensitive. As a result, 3HP was only produced upon incubation in dark anaerobic conditions. The oxygen sensitivity of glycerol dehydratase would have to be addressed before the direct photosynthetic $3 \mathrm{HP}$ production can be realized using this pathway.

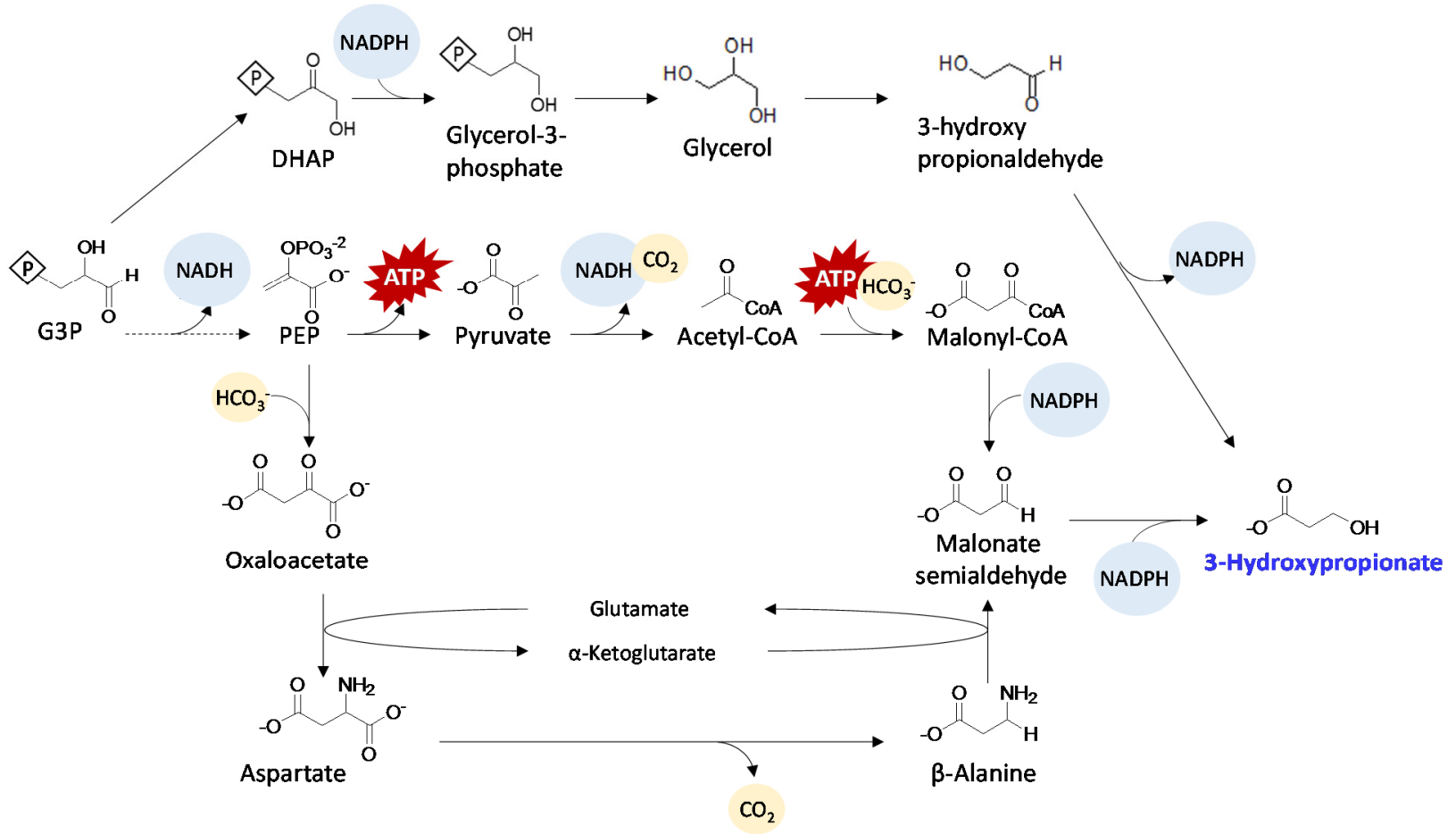

Figure 5. Schematics of 3HP production pathways. 
Using a different pathway, PCC 7942 was engineered to synthesize 3HP via two step reduction (Figure 5) from malonyl-CoA [37]. This pathway utilizes genes from the 3-hydroxypropionate/ 4-hydroxybutyrate carbon fixation pathway. The resulting strain produced $665 \mathrm{mg} / \mathrm{L}$ of $3 \mathrm{HP}, 10$-fold higher than that produced by strains expressing the glycerol dependent pathway. In the same study, a synthetic pathway was constructed to produce $3 \mathrm{HP}$ via $\beta$-alanine (Figure 5). The resulting strain expressing this $\beta$-alanine dependent pathway produced $186 \mathrm{mg} / \mathrm{L}$ of $3 \mathrm{HP}$. Compared to the glycerol dependent pathway for 3HP production, these two pathways do not have any known oxygen sensitivity. Therefore, these results again demonstrated the importance of using oxygen tolerant enzymes for cyanobacterial engineering. It is worth noting that $3 \mathrm{HP}$ is toxic at low concentrations to cyanobacteria [82]. Further strain engineering would be necessary for increasing $3 \mathrm{HP}$ productivity.

\section{4. p-Coumaric Acid}

Phenylpropanoids are a large group of secondary metabolites produced by plants with some having anti-inflammatory and antiviral properties. p-Coumaric acid is the precursor to these phenylpropanoids and can be produced via one step deamination from tyrosine. Recently, PCC 6803 was engineered to express tyrosine ammonia lyase (Tal) [40]. Interestingly, expression of Tal alone did not allow production of p-coumaric acid. Further analysis revealed the presence of a native laccase in PCC 6803 that degrades p-coumaric acid. Upon knocking out the laccase gene, the resulting strain was able to produce $82.6 \mathrm{mg} / \mathrm{L}$ of $\mathrm{p}$-coumaric acid. The Tal catalyzed reaction serves as a driving force for production of p-coumaric acid as the liberation of $\mathrm{NH}_{3}$ is thermodynamically favorable. A similar driving force has also been employed in the development of protein based biofuel production [83]. PCC 6803 was further engineered to convert p-coumaric acid into caffeic acid [84], also an important chemical with many bioactive properties and a precursor to many other bioactive products.

\section{Sugars}

Cyanobacteria are generally less tolerant to chemicals than other heterotrophic hosts such as E. coli and yeast, hindering its industrialization. Therefore, as an alternative approach, cyanobacteria are engineered to produce soluble sugars that are not toxic to cyanobacteria and can be directly utilized by heterotrophs. Sucrose is a natural product produced by cyanobacteria as an osmoprotectant. Sucrose can accumulate intracellularly at a concentration of around $300 \mathrm{mM}[85,86]$, representing a large amount of potential sugar that can be produced. To facilitate sucrose transport across the cellular membrane, sucrose permease (CscB), a sucrose/proton symporter, was expressed in PCC 7942 [46]. As cyanobacteria generate proton gradient from inside of thylakoid membranes and alkalinize the environment, it facilitates removal of sucrose from cytoplasm. The expression of $\mathrm{CscB}$ and knockout of glycogen synthesis enabled the production of sucrose up to $2.7 \mathrm{~g} / \mathrm{L}$ in engineered PCC 7942, representing a significant portion of carbon portioned into sucrose production. Glucose and fructose have also been produced by PCC 7942 [32] upon expression of invertase, which hydrolyzes sucrose.

In another study, sucrose production through metabolic engineering of PCC 6803 has been examined [47]. It was found that the sucrose accumulation of PCC 6803 was not as high as PCC 7942. Through overexpressing sucrose synthesis genes and knocking out the genes for glucosylglycerol formation, the resulting strain produced $140 \mathrm{mg} / \mathrm{L}$ of sucrose in 10 days. 
Mannitol is a sugar alcohol used in the pharmaceutical and food industries. To produce mannitol using recombinant cyanobacteria, PCC 7002 was engineered to express mannitol-1-phosphate dehydrogenase (MtlD) and mannitol-1-phosphatase (Mlp) [45]. Together with glycogen synthesis knocked out, the resulting strain produced $1.1 \mathrm{~g} / \mathrm{L}$ of mannitol. Interestingly, it was noted that mannitol was exported to the culture medium through an unknown mechanism. These relatively high flux photosynthetic sugar/sugar alcohol production studies indicated that the flux for sugar synthesis is naturally high in cyanobacteria as the overexpression of the genes related to the synthesis of upper glycolytic intermediates were not necessary.

\section{Diols and Polyol}

\subsection{2,3-Butanediol}

2,3-Butanediol is a natural fermentative product and synthesized from pyruvate. Using the same acetolactate synthase from the isobutanol biosynthesis, the production of 2,3-butanediol was achieved also with relatively high flux in both PCC 7942 [26] and PCC 6803 [25]. The engineered 2,3-butanediol producing strain from PCC 7942 was able to produce over $2.4 \mathrm{~g} / \mathrm{L}$ of 2,3-butanediol in 20 days, representing the second highest biochemical production titer reported. Subsequent improvements were made to balance the expression of pathway genes via combinatorial optimization of 5'UTR [87] and increase pyruvate pool by overexpressing enzymes between 3-phosphoglycerate to pyruvate [88]. Interestingly, one study showed that there is a hidden constitutive promoter within both alsS and $a d h$ [89]. This observation demonstrated that results obtained from traditional model organisms such as E. coli may or may not always translate into cyanobacteria because of both genetic and metabolic differences.

\subsection{1,2-Propanediol}

Similar to other diols, 1,2-propanediol is an important chemical feedstock. The pathway to 1,2-propanediol biosynthesis starts with DHAP, which is converted to methylglyoxal via methylglyoxal synthase. Methylglyoxal is then converted to 1,2-propanediol in two steps using two alcohol dehydrogenases. NADPH utilizing alcohol dehydrogenases were cloned into PCC 7942 together with methylglyoxal synthase. The resulting strain produced 1,2-propanediol with a titer of $150 \mathrm{mg} / \mathrm{L}$ in 10 days [24].

\subsection{Glycerol}

Glycerol has been extensively studied as a carbon source for producing many C3 chemicals such as 1,3-propanediol and 3-hydroxypropionate [90]. Glycerol is naturally synthesized in yeast as an osmoprotectant. Its production pathway starts with DHAP, which is then reduced to glycerol-3-phosphate. Once hydrolyzed, glycerol-3-phosphate becomes glycerol (Figure 5). The expression of Saccharomyces cerevisiae phosphoglycerol phosphatase (Gpp) in both PCC 6803 [27] and PCC 7942 [48] have yielded direct photosynthetic production of glycerol. In the PCC 6803 study, increasing the medium salt concentration and the expression of Gpp enabled production of glycerol up to $1.06 \mathrm{~g} / \mathrm{L}$. It was noticed that salt stress alone was able to induce glycerol synthesis in the wild type [27]. In the PCC 7942 study, glycerol production reached a titer of $1.17 \mathrm{~g} / \mathrm{L}$. In this study, glycerol further served as a precursor for producing 3-hydroxypropionate and dihydroxyacetone using engineered PCC 7942. Co-cultivation of 
glycerol producing cyanobacteria with Klebsiella pneumoniae also enabled the production of 1,3-propanediol. Glycerol productivity achieved in both studies are relatively high compared to other bioproducts. In addition to the non-toxic effect of glycerol to cyanobacteria, naturally high flux to glycerol-3-phosphate, especially under salt stress, contributed to glycerol's high flux biosynthesis. Furthermore, the dephosphorylation is also an irreversible reaction in vivo, further providing the driving force necessary for glycerol production.

\section{Conclusions}

Photoautotrophic production of biochemicals using metabolic engineered cyanobacteria is an attractive direction towards sustainability. Analysis of the chemical productions with higher titers often indicated that an effective metabolic driving force is necessary. It is worth noting that biochemical productions with titers exceeding $1 \mathrm{~g} / \mathrm{L}$ originate from pyruvate and other metabolites of sugar metabolism, potentially indicating that these metabolites are more accessible to heterologous pathways than acetylCoA. While some production pathways naturally have driving forces, many others do not. In those cases, a driving force may be engineered to increase the favorability of the pathway. Improving on these design strategies, the performance of cyanobacterial biochemical factories may also be improved.

\section{Acknowledgments}

This work was supported by the National Chiao Tung University start up fund and by the Ministry of Science and Technology, Taiwan, grant MOST 104-2311-B-009-001-MY2.

\section{Author Contributions}

Martin C. Lai and Ethan I. Lan wrote the manuscript.

\section{Conflicts of Interest}

The authors declare no conflict of interest.

\section{Abbreviations}

G3P, glyceraldehyde-3-phosphate;

DXP, 1-Deoxy-D-xylulose 5-phosphate;

MEP, methylerythritol 4-phosphate;

CDP-ME, 4-diphosphocytidyl-2-C-methylerythritol;

CDP-MEP, 4-diphosphocytidyl-2-C-methyl-D-erythritol 2-phosphate;

MEcPP, 2-C-methyl-D-erythritol 2,4-cyclopyrophosphate;

HMBPP, (E)-4-Hydroxy-3-methyl-but-2-enyl pyrophosphate;

IPP, Isopentenyl pyrophosphate;

DMAPP, Dimethylallyl pyrophosphate;

GPP, Geranyl pyrophosphate;

FPP, Farnesyl pyrophosphate;

HMG-CoA, 3-hydroxy-3-methylglutaryl-CoA; 
F6P, fructose-6-phosphate;

Glc6P, glucose-6-phosphate;

DHAP, dihydroxyacetone phosphate;

SAM, S-adenosylmethionine.

\section{References}

1. Nakao, M.; Okamoto, S.; Kohara, M.; Fujishiro, T.; Fujisawa, T.; Sato, S.; Tabata, S.; Kaneko, T.; Nakamura, Y. Cyanobase: The cyanobacteria genome database update 2010. Nucleic Acids Res. 2010, 38, D379-D381.

2. Dempo, Y.; Ohta, E.; Nakayama, Y.; Bamba, T.; Fukusaki, E. Molar-based targeted metabolic profiling of cyanobacterial strains with potential for biological production. Metabolites 2014, 4, 499-516.

3. Hasunuma, T.; Kikuyama, F.; Matsuda, M.; Aikawa, S.; Izumi, Y.; Kondo, A. Dynamic metabolic profiling of cyanobacterial glycogen biosynthesis under conditions of nitrate depletion. J. Exp. Bot. 2013, 64, 2943-2954.

4. Nakajima, T.; Kajihata, S.; Yoshikawa, K.; Matsuda, F.; Furusawa, C.; Hirasawa, T.; Shimizu, H. Integrated metabolic flux and omics analysis of Synechocystis sp. PCC 6803 under mixotrophic and photoheterotrophic conditions. Plant Cell Physiol. 2014, 55, 1605-1612.

5. Triana, J.; Montagud, A.; Siurana, M.; Fuente, D.; Urchueguia, A.; Gamermann, D.; Torres, J.; Tena, J.; de Cordoba, P.F.; Urchueguia, J.F. Generation and evaluation of a genome-scale metabolic network model of Synechococcus elongatus PCC7942. Metabolites 2014, 4, 680-698.

6. Knoop, H.; Grundel, M.; Zilliges, Y.; Lehmann, R.; Hoffmann, S.; Lockau, W.; Steuer, R. Flux balance analysis of cyanobacterial metabolism: The metabolic network of Synechocystis sp. PCC 6803. PLoS Comput. Biol. 2013, 9, e1003081.

7. Mueller, T.J.; Berla, B.M.; Pakrasi, H.B.; Maranas, C.D. Rapid construction of metabolic models for a family of cyanobacteria using a multiple source annotation workflow. BMC Syst. Biol. 2013, doi:10.1186/1752-0509-7-142.

8. Kufryk, G.I.; Sachet, M.; Schmetterer, G.; Vermaas, W.F.J. Transformation of the cyanobacterium Synechocystis sp. PCC 6803 as a tool for genetic mapping: Optimization of efficiency. FEMS Microbiol. Lett. 2002, 206, 215-219.

9. Bustos, S.A.; Golden, S.S. Expression of the psbDII gene in Synechococcus sp. Strain PCC 7942 requires sequences downstream of the transcription start site. J. Bacteriol. 1991, 173, 7525-7533.

10. ElhaI, J.; Vepritskiy, A.; MuroPastor, A.M.; Flores, E.; Wolk, C.P. Reduction of conjugal transfer efficiency by three restriction activities of Anabaena sp. Strain PCC 7120. J. Bacteriol. 1997, 179, 1998-2005.

11. Gao, Z.X.; Zhao, H.; Li, Z.M.; Tan, X.M.; Lu, X.F. Photosynthetic production of ethanol from carbon dioxide in genetically engineered cyanobacteria. Energy Environ. Sci. 2012, 5, 9857-9865.

12. Dexter, J.; Fu, P.C. Metabolic engineering of cyanobacteria for ethanol production. Energy Environ. Sci. 2009, 2, 857-864. 
13. Lan, E.I.; Ro, S.Y.; Liao, J.C. Oxygen-tolerant coenzyme a-acylating aldehyde dehydrogenase facilitates efficient photosynthetic n-butanol biosynthesis in cyanobacteria. Energy Environ. Sci. 2013, 6, 2672-2681.

14. Deng, M.D.; Coleman, J.R. Ethanol synthesis by genetic engineering in cyanobacteria. Appl. Environ. Microbiol. 1999, 65, 523-528.

15. Hirokawa, Y.; Suzuki, I.; Hanai, T. Optimization of isopropanol production by engineered cyanobacteria with a synthetic metabolic pathway. J. Biosci. Bioeng. 2015, 119, 585-590.

16. Kusakabe, T.; Tatsuke, T.; Tsuruno, K.; Hirokawa, Y.; Atsumi, S.; Liao, J.C.; Hanai, T. Engineering a synthetic pathway in cyanobacteria for isopropanol production directly from carbon dioxide and light. Metab. Eng. 2013, 20, 101-108.

17. Lan, E.I.; Liao, J.C. Atp drives direct photosynthetic production of 1-butanol in cyanobacteria. Proc. Natl. Acad. Sci. USA 2012, 109, 6018-6023.

18. Lan, E.I.; Liao, J.C. Metabolic engineering of cyanobacteria for 1-butanol production from carbon dioxide. Metab. Eng. 2011, 13, 353-363.

19. Atsumi, S.; Higashide, W.; Liao, J.C. Direct photosynthetic recycling of carbon dioxide to isobutyraldehyde. Nat. Biotechnol. 2009, 27, 1177-1180.

20. Varman, A.M.; Xiao, Y.; Pakrasi, H.B.; Tang, Y.J.J. Metabolic engineering of Synechocystis sp. strain PCC 6803 for isobutanol production. Appl. Environ. Microbiol. 2013, 79, 908-914.

21. Shen, C.R.; Liao, J.C. Photosynthetic production of 2-methyl-1-butanol from $\mathrm{CO}_{2}$ in cyanobacterium Synechococcus elongatus PCC7942 and characterization of the native acetohydroxyacid synthase. Energy Environ. Sci. 2012, 5, 9574-9583.

22. Tan, X.M.; Yao, L.; Gao, Q.Q.; Wang, W.H.; Qi, F.X.; Lu, X.F. Photosynthesis driven conversion of carbon dioxide to fatty alcohols and hydrocarbons in cyanobacteria. Metab. Eng. 2011, 13, 169-176.

23. Gao, Q.Q.; Wang, W.H.; Zhao, H.; Lu, X.F. Effects of fatty acid activation on photosynthetic production of fatty acid-based biofuels in Synechocystis sp. PCC6803. Biotechnol. Biofuels 2012, 5, 17.

24. Li, H.; Liao, J.C. Engineering a cyanobacterium as the catalyst for the photosynthetic conversion of $\mathrm{CO}_{2}$ to 1,2-propanediol. Microb. Cell Fact. 2013, doi:10.1186/1475-2859-12-4.

25. Savakis, P.E.; Angermayr, S.A.; Hellingwerf, K.J. Synthesis of 2,3-butanediol by Synechocystis sp. PCC6803 via heterologous expression of a catabolic pathway from lactic acid- and enterobacteria. Metab. Eng. 2013, 20, 121-130.

26. Oliver, J.W.; Machado, I.M.; Yoneda, H.; Atsumi, S. Cyanobacterial conversion of carbon dioxide to 2,3-butanediol. Proc. Natl. Acad. Sci. USA 2013, 110, 1249-1254.

27. Savakis, P.; Tan, X.M.; Du, W.; dos Santos, F.B.; Lu, X.F.; Hellingwerf, K.J. Photosynthetic production of glycerol by a recombinant cyanobacterium. J. Biotechnol. 2015, 195, 46-51.

28. Wang, Y.; Tao, F.; Ni, J.; Li, C.; Xu, P. Production of $\mathrm{C} 3$ platform chemicals from $\mathrm{CO}_{2}$ by genetically engineered cyanobacteria. Green Chem. 2015, 17, 3100-3110.

29. Varman, A.M.; Yu, Y.; You, L.; Tang, Y.J.J. Photoautotrophic production of d-lactic acid in an engineered cyanobacterium. Microb. Cell Fact. 2013, doi:10.1186/1475-2859-12-117.

30. Zhou, J.; Zhang, H.F.; Meng, H.K.; Zhang, Y.P.; Li, Y. Production of optically pure d-lactate from $\mathrm{CO}_{2}$ by blocking the phb and acetate pathways and expressing d-lactate dehydrogenase in cyanobacterium Synechocystis sp. PCC 6803. Process Biochem. 2014, 49, 2071-2077. 
31. Li, C.; Tao, F.; Ni, J.; Wang, Y.; Yao, F.; Xu, P. Enhancing the light-driven production of d-lactate by engineering cyanobacterium using a combinational strategy. Sci. Rep. 2015, 5, 9777.

32. Niederholtmeyer, H.; Wolfstadter, B.T.; Savage, D.F.; Silver, P.A.; Way, J.C. Engineering cyanobacteria to synthesize and export hydrophilic products. Appl. Environ. Microbiol. 2010, 76, 3462-3466.

33. Angermayr, S.A.; Hellingwerf, K.J. On the use of metabolic control analysis in the optimization of cyanobacterial biosolar cell factories. J. Phys. Chem. B 2013, 117, 11169-11175.

34. Angermayr, S.A.; van der Woude, A.D.; Correddu, D.; Vreugdenhil, A.; Verrone, V.; Hellingwerf, K.J. Exploring metabolic engineering design principles for the photosynthetic production of lactic acid by Synechocystis sp. PCC6803. Biotechnol. Biofuels 2014, 7, 99.

35. Angermayr, S.A.; Paszota, M.; Hellingwerf, K.J. Engineering a cyanobacterial cell factory for production of lactic acid. Appl. Environ. Microbiol. 2012, 78, 7098-7106.

36. Joseph, A.; Aikawa, S.; Sasaki, K.; Tsuge, Y.; Matsuda, F.; Tanaka, T.; Kondo, A. Utilization of lactic acid bacterial genes in Synechocystis sp. PCC 6803 in the production of lactic acid. Biosci. Biotech. Biochem. 2013, 77, 966-970.

37. Lan, E.I.; Chuang, D.S.; Shen, C.R.; Lee, A.M.; Ro, S.Y.; Liao, J.C. Metabolic engineering of cyanobacteria for photosynthetic 3-hydroxypropionic acid production from $\mathrm{CO}_{2}$ using Synechococcus elongatus PCC 7942. Metab. Eng. 2015, 31, 163-170.

38. Wang, B.; Pugh, S.; Nielsen, D.R.; Zhang, W.; Meldrum, D.R. Engineering cyanobacteria for photosynthetic production of 3-hydroxybutyrate directly from $\mathrm{CO}_{2}$. Metab. Eng. 2013, 16C, 68-77.

39. Chin, T.; Sano, M.; Takahashi, T.; Ohara, H.; Aso, Y. Photosynthetic production of itaconic acid in Synechocystis sp. PCC6803. J. Biotechnol. 2015, 195, 43-45.

40. Xue, Y.; Zhang, Y.; Cheng, D.; Daddy, S.; He, Q.F. Genetically engineering Synechocystis sp. pasteur culture collection 6803 for the sustainable production of the plant secondary metabolite p-coumaric acid. Proc. Natl. Acad. Sci. USA 2014, 111, 9449-9454.

41. Liu, X.Y.; Sheng, J.; Curtiss, R. Fatty acid production in genetically modified cyanobacteria. Proc. Natl. Acad. Sci. USA 2011, 108, 6899-6904.

42. Ruffing, A.M. Improved free fatty acid production in cyanobacteria with Synechococcus sp. PCC 7002 as host. Front. Bioeng. Biotechnol. 2014, 2, 17.

43. Ruffing, A.M.; Jones, H.D. Physiological effects of free fatty acid production in genetically engineered Synechococcus elongatus PCC 7942. Biotechnol. Bioeng. 2012, 109, 2190-2199.

44. Ruffing, A.M. Borrowing genes from chlamydomonas reinhardtii for free fatty acid production in engineered cyanobacteria. J. Appl. Phycol. 2013, 25, 1495-1507.

45. Jacobsen, J.H.; Frigaard, N.U. Engineering of photosynthetic mannitol biosynthesis from $\mathrm{CO}_{2}$ in a cyanobacterium. Metab. Eng. 2014, 21, 60-70.

46. Ducat, D.C.; Avelar-Rivas, J.A.; Way, J.C.; Silver, P.A. Rerouting carbon flux to enhance photosynthetic productivity. Appl. Environ. Microbiol. 2012, 78, 2660-2668.

47. Du, W.; Liang, F.Y.; Duan, Y.K.; Tan, X.M.; Lu, X.F. Exploring the photosynthetic production capacity of sucrose by cyanobacteria. Metab. Eng. 2013, 19, 17-25.

48. Tan, X.M.; Du, W.; Lu, X.F. Photosynthetic and extracellular production of glucosylglycerol by genetically engineered and gel-encapsulated cyanobacteria. Appl. Microbiol. Biotechnol. 2015, 99, 2147-2154. 
49. Guerrero, F.; Carbonell, V.; Cossu, M.; Correddu, D.; Jones, P.R. Ethylene synthesis and regulated expression of recombinant protein in Synechocystis sp. PCC 6803. PLoS ONE 2012, 7, e50470.

50. Ungerer, J.; Tao, L.; Davis, M.; Ghirardi, M.; Maness, P.-C.; Yu, J. Sustained photosynthetic conversion of $\mathrm{CO}_{2}$ to ethylene in recombinant cyanobacterium Synechocystis 6803. Energy Environ. Sci. 2012, 5, 8998-9006.

51. Jindou, S.; Ito, Y.; Mito, N.; Uematsu, K.; Hosoda, A.; Tamura, H. Engineered platform for bioethylene production by a cyanobacterium expressing a chimeric complex of plant enzymes. ACS Synth. Biol. 2014, 3, 487-496.

52. Takahama, K.; Matsuoka, M.; Nagahama, K.; Ogawa, T. Construction and analysis of a recombinant cyanobacterium expressing a chromosomally inserted gene for an ethylene-forming enzyme at the psbai locus. J. Biosci. Bioeng. 2003, 95, 302-305.

53. Bentley, F.K.; Melis, A. Diffusion-based process for carbon dioxide uptake and isoprene emission in gaseous/aqueous two-phase photobioreactors by photosynthetic microorganisms. Biotechnol. Bioeng. 2012, 109, 100-109.

54. Bentley, F.K.; Zurbriggen, A.; Melis, A. Heterologous expression of the mevalonic acid pathway in cyanobacteria enhances endogenous carbon partitioning to isoprene. Mol. Plant 2014, 7, 71-86.

55. Lindberg, P.; Park, S.; Melis, A. Engineering a platform for photosynthetic isoprene production in cyanobacteria, using Synechocystis as the model organism. Metab. Eng. 2010, 12, 70-79.

56. Kiyota, H.; Okuda, Y.; Ito, M.; Hirai, M.Y.; Ikeuchi, M. Engineering of cyanobacteria for the photosynthetic production of limonene from $\mathrm{CO}_{2}$. J. Biotechnol. 2014, 185, 1-7.

57. Davies, F.K.; Work, V.H.; Beliaev, A.S.; Posewitz, M.C. Engineering limonene and bisabolene production in wild type and a glycogen-deficient mutant of Synechococcus sp. PCC 7002. Front. Bioeng. Biotechnol. 2014, 2, 21.

58. Halfmann, C.; Gu, L.P.; Zhou, R.B. Engineering cyanobacteria for the production of a cyclic hydrocarbon fuel from $\mathrm{CO}_{2}$ and $\mathrm{H}_{2} \mathrm{O}$. Green Chem. 2014, 16, 3175-3185.

59. Halfmann, C.; Gu, L.P.; Gibbons, W.; Zhou, R.B. Genetically engineering cyanobacteria to convert $\mathrm{CO}_{2}$, water, and light into the long-chain hydrocarbon farnesene. Appl. Microbiol. Biotechnol. 2014, 98, 9869-9877.

60. Qi, Q.G.; Hao, M.; Ng, W.O.; Slater, S.C.; Baszis, S.R.; Weiss, J.D.; Valentin, H.E. Application of the Synechococcus nirA promoter to establish an inducible expression system for engineering the Synechocystis tocopherol pathway. Appl. Environ. Microbiol. 2005, 71, 5678-5684.

61. Reinsvold, R.E.; Jinkerson, R.E.; Radakovits, R.; Posewitz, M.C.; Basu, C. The production of the sesquiterpene beta-caryophyllene in a transgenic strain of the cyanobacterium Synechocystis. J. Plant. Physiol. 2011, 168, 848-852.

62. Formighieri, C.; Melis, A. Regulation of beta-phellandrene synthase gene expression, recombinant protein accumulation, and monoterpene hydrocarbons production in Synechocystis transformants. Planta 2014, 240, 309-324.

63. Bentley, F.; García-Cerdán, J.; Chen, H.-C.; Melis, A. Paradigm of monoterpene ( $\beta$-phellandrene) hydrocarbons production via photosynthesis in cyanobacteria. Bioenergy Res. 2013, 6, 917-929.

64. Zhou, J.; Zhang, H.; Zhang, Y.; Li, Y.; Ma, Y. Designing and creating a modularized synthetic pathway in cyanobacterium Synechocystis enables production of acetone from carbon dioxide. Metab. Eng. 2012, 14, 394-400. 
65. Kageyama, H.; Waditee-Sirisattha, R.; Sirisattha, S.; Tanaka, Y.; Mahakhant, A.; Takabe, T. Improved alkane production in nitrogen-fixing and halotolerant cyanobacteria via abiotic stresses and genetic manipulation of alkane synthetic genes. Curr. Microbiol. 2015, 71, 115-120.

66. Stal, L.J.; Moezelaar, R. Fermentation in cyanobacteria. FEMS Microbiol. Rev. 1997, 21, 179-211.

67. Shen, C.R.; Lan, E.I.; Dekishima, Y.; Baez, A.; Cho, K.M.; Liao, J.C. Driving forces enable high-titer anaerobic 1-butanol synthesis in Escherichia coli. Appl. Environ. Microbiol. 2011, 77, 2905-2915.

68. Bond-Watts, B.B.; Bellerose, R.J.; Chang, M.C.Y. Enzyme mechanism as a kinetic control element for designing synthetic biofuel pathways. Nat. Chem. Biol. 2011, 7, 222-227.

69. Atsumi, S.; Liao, J.C. Directed evolution of Methanococcus jannaschii citramalate synthase for biosynthesis of 1-propanol and 1-butanol by Escherichia coli. Appl. Environ. Microbiol. 2008, 74, $7802-7808$.

70. Liu, X.; Fallon, S.; Sheng, J.; Curtiss, R., 3rd. $\mathrm{CO}_{2}$-limitation-inducible green recovery of fatty acids from cyanobacterial biomass. Proc. Natl. Acad. Sci. USA 2011, 108, 6905-6908.

71. Han, J.; McCarthy, E.D.; Hoeven, W.V.; Calvin, M.; Bradley, W.H. Organic geochemical studies, ii. A preliminary report on the distribution of aliphatic hydrocarbons in algae, in bacteria, and in a recent lake sediment. Proc. Natl. Acad. Sci. USA 1968, 59, 29-33.

72. Schirmer, A.; Rude, M.A.; Li, X.; Popova, E.; del Cardayre, S.B. Microbial biosynthesis of alkanes. Science 2010, 329, 559-562.

73. Mendez-Perez, D.; Herman, N.A.; Pfleger, B.F. A desaturase gene involved in the formation of 1,14-nonadecadiene in Synechococcus sp. Strain PCC 7002. Appl. Environ. Microbiol. 2014, 80, 6073-6079.

74. Peramuna, A.; Morton, R.; Summers, M.L. Enhancing alkane production in cyanobacterial lipid droplets: A model platform for industrially relevant compound production. Life 2015, 5, 1111-1126.

75. Wang, W.H.; Liu, X.F.; Lu, X.F. Engineering cyanobacteria to improve photosynthetic production of alka(e)nes. Biotechnol. Biofuels 2013, 6, doi:10.1186/1754-6834-6-69.

76. Choi, Y.J.; Lee, S.Y. Microbial production of short-chain alkanes. Nature 2013, 502, 571-574.

77. Fukuda, H.; Sakai, M.; Nagahama, K.; Fujii, T.; Matsuoka, M.; Inoue, Y.; Ogawa, T. Heterologous expression of the gene for the ethylene-forming enzyme from Pseudomonas syringae in the cyanobacterium Synechococcus. Biotechnol. Lett. 1994, 16, 1-6.

78. Sakai, M.; Ogawa, T.; Matsuoka, M.; Fukuda, H. Photosynthetic conversion of carbon dioxide to ethylene by the recombinant cyanobacterium, Synechococcus sp. PCC 7942, which harbors a gene for the ethylene-forming enzyme of Pseudomonas syringae. J. Ferment. Bioeng. 1997, 84, 434-443.

79. Lee, T.C.; Xiong, W.; Paddock, T.; Carrieri, D.; Chang, I.F.; Chiu, H.F.; Ungerer, J.; Hank Juo, S.H.; Maness, P.C.; Yu, J. Engineered xylose utilization enhances bio-products productivity in the cyanobacterium Synechocystis sp. PCC 6803. Metab. Eng. 2015, 30, 179-189.

80. Englund, E.; Andersen-Ranberg, J.; Miao, R.; Hamberger, B.; Lindberg, P. Metabolic engineering of Synechocystis sp. PCC 6803 for production of the plant diterpenoid manoyl oxide. ACS Synth. Biol. 2015, doi:10.1021/acssynbio.5b00070.

81. Hollinshead, W.D.; Varman, A.M.; You, L.; Hembree, Z.; Tang, Y.J.J. Boosting d-lactate production in engineered cyanobacteria using sterilized anaerobic digestion effluents. Bioresour. Technol. 2014, $169,462-467$. 
82. Begemann, M.B.; Zess, E.K.; Walters, E.M.; Schmitt, E.F.; Markley, A.L.; Pfleger, B.F. An organic acid based counter selection system for cyanobacteria. PLoS ONE 2013, 8, e76594.

83. Huo, Y.X.; Cho, K.M.; Rivera, J.G.L.; Monte, E.; Shen, C.R.; Yan, Y.J.; Liao, J.C. Conversion of proteins into biofuels by engineering nitrogen flux. Nat. Biotechnol. 2011, 29, 346-351.

84. Xue, Y.; Zhang, Y.; Grace, S.; He, Q. Functional expression of an Arabidopsis p450 enzyme, p-coumarate-3-hydroxylase, in the cyanobacterium Synechocystis PCC 6803 for the biosynthesis of caffeic acid. J. Appl. Phycol. 2014, 26, 219-226.

85. Klahn, S.; Hagemann, M. Compatible solute biosynthesis in cyanobacteria. Environ. Microbiol. 2011, 13, 551-562.

86. Suzuki, E.; Ohkawa, H.; Moriya, K.; Matsubara, T.; Nagaike, Y.; Iwasaki, I.; Fujiwara, S.; Tsuzuki, M.; Nakamura, Y. Carbohydrate metabolism in mutants of the cyanobacterium Synechococcus elongatus PCC 7942 defective in glycogen synthesis. Appl. Environ. Microbiol. 2010, 76, 3153-3159.

87. Oliver, J.W.; Machado, I.M.; Yoneda, H.; Atsumi, S. Combinatorial optimization of cyanobacterial 2,3-butanediol production. Metab. Eng. 2014, 22, 76-82.

88. Oliver, J.W.; Atsumi, S. A carbon sink pathway increases carbon productivity in cyanobacteria. Metab. Eng. 2015, 29, 106-112.

89. Nozzi, N.E.; Atsumi, S. Genome engineering of the 2,3-butanediol biosynthetic pathway for tight regulation in cyanobacteria. ACS Synth. Biol. 2015, doi:10.1021/acssynbio.5b00057.

90. Clomburg, J.M.; Gonzalez, R. Anaerobic fermentation of glycerol: A platform for renewable fuels and chemicals. Trends Biotechnol. 2013, 31, 20-28.

(C) 2015 by the authors; licensee MDPI, Basel, Switzerland. This article is an open access article distributed under the terms and conditions of the Creative Commons Attribution license (http://creativecommons.org/licenses/by/4.0/). 